\title{
Race Differences in Tipping: Testing the Role of Norm Familiarity
}

Cornell Hospitality Quarterly 52(I) 73-80

(C) The Author(s) 2011

Reprints and permission:

sagepub.com/journalsPermissions.nav DOI: $10.1 \mid 77 / 1938965510389297$

http://cqx.sagepub.com

@SAGE

\section{By Michael Lynn}

\begin{abstract}
On average, blacks tip less than whites in the United States. As a result, many servers dislike waiting on black tables and deliver inferior service to those blacks seated in their sections. Furthermore, this race difference makes it difficult to attract and retain waitstaff in predominately black neighborhoods, which makes such neighborhoods less attractive places for corporations to locate full-service restaurants. To address these issues, race differences in tipping need to be sizably reduced, which requires an understanding of their underlying causes. This study tests and supports the role of norm familiarity in producing race differences in tipping by demonstrating that norm awareness mediates those differences in tipping and that race does not moderate the effects of norm awareness on tipping. These results support the idea that race differences in tipping can be sizably reduced by educating blacks about appropriate tipping norms, so restaurant managers as well as major industry organizations are encouraged to engage in such educational campaigns.
\end{abstract}

\section{Keywords}

tipping, race differences, social norms

African Americans are widely perceived within the restaurant industry as poor tippers. In fact, one recent survey of more than a thousand servers from across the United States found that more than 65 percent rated African Americans as "below average tippers" (McCall and Lynn 2009). This perception poses a problem for managers in the restaurant industry, because it leads many servers to dislike waiting on black tables and to deliver inferior service to those blacks seated in their sections (Rusche and Brewster 2008). Furthermore, servers' perceptions of black tippers makes it difficult to recruit and retain waitstaff in predominately black neighborhoods (Amer 2002), which in turn makes restaurant corporations less likely to locate full-service restaurants in those neighborhoods (Wallace 2001).

Complicating efforts to address these problems is the fact that servers' perceptions of black tippers are grounded in reality. Studies have found that black patrons are less likely than whites to base their tips on bill size and that blacks leave smaller tips as a percentage of the bill than do whites (Lynn 2004a, 2009; Lynn and Thomas-Haysbert 2003; Lynn et al. 2008). Moreover, these race differences persist even after controlling for customer education and income and for service quality (Lynn 2006). These findings suggest that the problems associated with servers' perceptions of black tippers cannot be solved merely by hiring nonracist servers or by telling servers that their perceptions are incorrect. Solving these problems requires either a reduction in the race differences in tipping or use of something other than tips to motivate waitstaff.

In a 2004 article in this journal, I argued that black-white differences in restaurant tipping were due to differences in familiarity with the 15 to 20 percent restaurant tipping norm (see Exhibit 1). I proposed at that time that those race differences in tipping could be reduced with an educational campaign designed to increase blacks' awareness of the tipping norm (see Lynn 2004b). Consistent with this idea, a nationwide telephone survey found that only 37 percent of blacks knew that the expected or normative restaurant tip was 15 to 20 percent of the bill size, as compared to 71 percent of whites. Although I replicated that finding in a second national telephone survey (Lynn 2006), that finding is insufficient to support the thesis that race differences in tipping behavior are caused by differences in norm familiarity or that reducing the familiarity differences would cause changes in blacks' tipping behavior. Demonstrating such a mediation effect would require either manipulating familiarity with the tipping norm and observing its effect on race differences in tipping behavior or (failing that) measuring both norm awareness and tipping behavior and finding that race differences in behavior are attenuated after controlling for norm awareness. No such tests have been reported in the existing literature.

In the absence of data permitting tests of mediation, I have supported my contention that race differences in tipping are mediated by differences in awareness of tipping norms by 


\section{Exhibit 1: \\ Model Depicting Norm Awareness as a Moderator of Race Differences in Tipping Behavior}

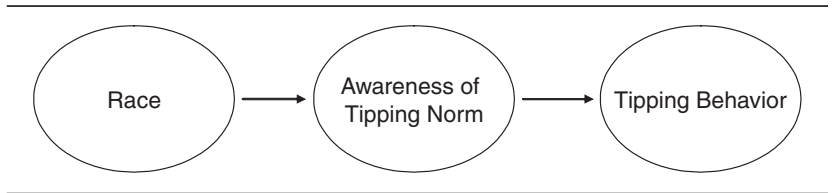

arguing that such norms clearly guide the tipping behavior of whites but cannot guide the behavior of blacks who are unaware of them (Lynn 2004b). However, this argument rests on the questionable assumption that awareness of tipping norms will affect the tips of blacks, as it apparently does the tips of whites. It is possible that blacks who become aware of tipping norms will simply choose to not comply with them.

Norm compliance, including tipping, is generally motivated by either an internalization of the norm or a concern for the social consequences of norm violation (Lynn 2009). Both motives may be weaker among blacks than among whites. Blacks are less likely than whites to know the norm (Lynn 2004b, 2006) and, thus, are less able to pass it on to their children or friends. As a consequence, blacks are probably more likely to learn tipping norms from strangers. Since people are more likely to identify with family and friends than with strangers, this conjectured race difference in source of norm awareness may reduce blacks' internalization of those tipping norms with which they are familiar. Similarly, the fact that blacks comply with tipping norms less than do whites may reduce the social pressure to comply felt by those blacks who are aware of the norms, because people tend to look to similar others as their reference groups. These possibilities suggest that awareness of tipping norms may interact with race to affect tipping behavior such that race differences are greater when norm awareness is high or (equivalently) that norm awareness effects on tipping are greater for whites than for blacks (see Exhibit 2).

The data and analyses reported in this article were primarily intended to provide needed tests of the ideas that familiarity with the restaurant tipping norm mediates or moderates race effects on restaurant tipping behavior. Specifically, survey data about white and black consumers' familiarity with tipping norms and their tipping behaviors are analyzed to see whether race differences in behavior are attenuated after controlling for norm awareness. The data are also analyzed to see whether norm awareness interacts with race to affect tipping behavior. Some of the data from this survey have been reported in my 2009 article, including the data on race differences in tipping behavior. However, that study was not focused on race differences, and I did not report on the survey's data about race differences in familiarity with tipping norms. Thus, this article goes substantially beyond that 2009 article and provides new findings that bear on an important issue in restaurant

\section{Exhibit 2:}

Models Depicting Race as a Moderator of Norm Awareness Effects on Tipping and Norm Awareness as a Moderator of Race Differences in TippingMathematically and Empirically, the Models Are the Same
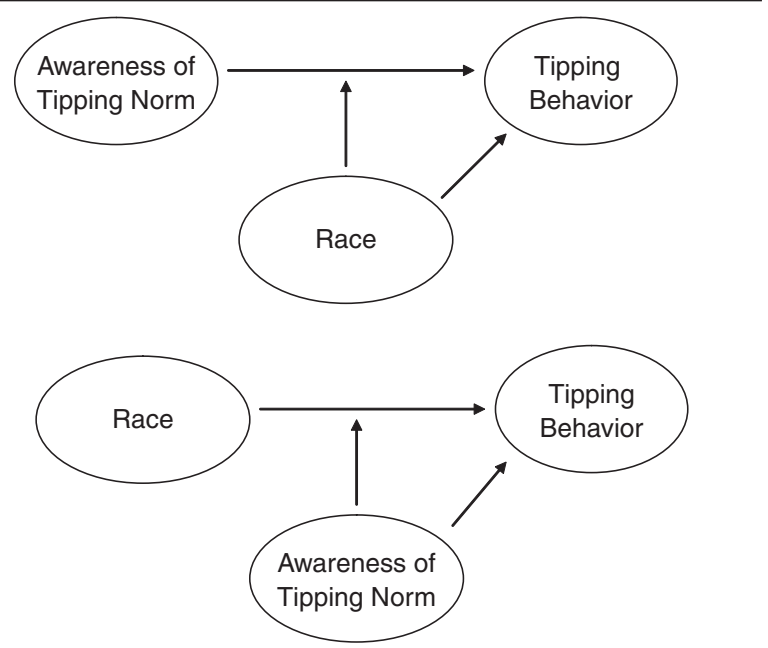

management. A secondary purpose of the article is to go beyond the existing literature by examining for the first time race differences in awareness of other (nonrestaurant) tipping norms and their effects on tipping behavior.

\section{Method}

Sample

A total of 10,729 members of the Zoomerang.com consumer panel were asked via e-mail to complete a brief web-based survey about tipping norms and habits. The company sent out the invitations in waves until it achieved target numbers of at least 100 black respondents with no college education, 100 black respondents with some college education, 100 white respondents with no college education, and 100 white respondents with some college education. These numbers were achieved after 831 people responded, giving a response rate of 7.75 percent. Respondents in the final sample ranged in age from seventeen to eighty-six years with a mean age of forty-three. Sixty eight percent were female; 46 percent were black; 65 percent had at least some college education; and 38 percent earned $\$ 50,000$ or more a year. Although not representative of the U.S. population, this sample is heterogeneous and well suited for the purpose of examining race differences in tipping.

\section{Survey Questions}

Restaurant tipping behavior. Following the Lynn and Thomas-Haysbert (2003) study, participants were asked, 
"How much do you usually tip restaurant waiters and waitresses who give you good service?" The response options were "nothing"; "\$1-2"; "\$3 or more"; "less than $10 \%$ of the bill"; " $10-15 \%$ of the bill"; " $15-20 \%$ of the bill"; "more than $20 \%$ of the bill"; and "not applicable (I never eat at restaurants)." These responses were used to create two variablestip type $($ dollar $=0$, percent $=1)$ and percentage tip size $($ less than 10 percent coded as $8.5,10$ to 15 percent coded as 12.5 , 15 to 20 percent coded as 17.5 , and more than 20 percent coded as 22.5). A third variable, dollar tip size, was not analyzed in this study because I found no reliable race effect on this measure in the 2009 study.

Stiffing behavior outside of restaurants. Participants were asked, "How often do you tip the following service providers when they serve you?" The list of service providers included bartenders, hair cutters, hotel maids, luggage handlers at hotels or airports, parking valets, pizza delivery drivers, and taxi drivers. The response options were " 1 -always/usually tip"; "2_-sometimes tip"; "3-don't tip"; and "4_-don't use this service," so higher numbers represent a greater likelihood of stiffing that service provider. Participants responding "don't use this service" were given a missing value on these variables. Also, data on (and analyses of) hotel maids and luggage handlers were not included in this article, because there were no reliable $(p<.05)$ race differences in stiffing of these service providers in the current data.

Restaurant tipping norm. Participants were asked, "How much are people in the United States generally expected to tip restaurant waiters and waitresses?" The response options were "nothing"; "\$1-2"; "\$3 or more"; "less than 10\% of the bill"; " $10-15 \%$ of the bill"; " $15-20 \%$ of the bill"; "more than $20 \%$ of the bill"; and "don't know." Since the restaurant tipping norm in the United States calls for tipping 15 to 20 percent of the bill, those participants responding with any of the percentage responses were coded as knowing the restaurant tipping norm in all analyses of restaurant tip type, but only those responding " $15-20 \%$ of the bill" were coded as knowing the restaurant tipping norm in the analyses of restaurant tip percentage.

Nonrestaurant tipping norms. Participants were asked, "Which of the following other service providers are people generally expected to tip in the United States?" In addition to some nontipped occupations, the list of service providers included the following tipped occupations: bartenders, hair cutters, hotel maids, luggage handlers at hotels or airports, parking valets, pizza delivery drivers, and taxi drivers. The response options were "tipped," "not tipped," and "don't know." Participants responding "tipped" for a given tipped occupation were coded as having some knowledge of the tipping norm for that occupation. Again, data on (and analyses of) hotel maids and luggage handlers were not included in this article.

Demographic characteristics. Participants were asked to provide information about their age (in years), $\operatorname{sex}(\mathrm{M}=1, \mathrm{~F}=2)$, race (white $=1$, black $=2 ; 36$ respondents not answering this questions or indicating that they were other than white or black were dropped from analysis), education (using a 7-point ordinal scale from 1 = "8th grade or less" to 7 = "post-graduate"), and income (using a nine point ordinal scale from $1=$ "under $\$ 15,000 "$ to $9=$ " $\$ 100,000$ or more").

\section{Results}

Descriptive results. Sample sizes and means and standard deviations of the variables in this study are presented in Exhibit 3. Note that I measured different levels of awareness for different tipping norms and that this is reflected in the mean awareness scores for the different norms. As expected, the respondents' awareness that restaurant tips should be 15 to 20 percent of the bill is lower than their awareness of the general norm that restaurant tips should be at least some percentage of the bill and their awareness that the other service providers are customarily tipped. Measuring these different levels of knowledge about tipping norms was appropriate given the level of tipping behavior each was thought to mediateknowledge that restaurant tips should be 15 to 20 percent of the bill was tested as a mediator of race differences in the level of restaurant percentage tips, while knowledge that restaurant tips should be a percentage of the bill was tested as a mediator only for tip type (i.e., dollar tip or percentage tip), and knowledge that other service providers are customarily tipped was tested as a mediator only for frequency of stiffing (or not tipping) those other service providers.

Norm awareness as a mediator. According to Baron and Kenny (1986), the mediation of an independent variable's effect on a dependent variable can be established by demonstrating that the proposed mediator is related to both the independent variable and the dependent variable after controlling for the independent variable. In this case, norm awareness can be said to mediate race effects on tipping behavior if the races differ in norm awareness and if norm awareness predicts tipping behavior after controlling for race. I assessed these effects in regression analyses that also controlled for respondent age, sex, education, and income. The critical results are presented in Exhibit 4. The regression coefficients - for race effects on norm awareness and for norm awareness effects on tipping behavior after controlling for race-were also used to calculate values for the Sobel test (also presented in Exhibit 4), which is another way to assess the statistical reliability of mediation effects. Based on the results of all these analyses, norm awareness does mediate race effects on restaurant tip type (Sobel test $=-5.96, p<.001$ ), restaurant tip percentages (Sobel test $=-6.53, p<.001$ ), and the stiffing of hair cutters (Sobel test $=3.53, p<.001)$ and pizza delivery drivers (Sobel test $=$ $3.00, p<.01)$. However, because there are no race differences in the awareness of tipping customs for certain service providers, it does not mediate race effects on the stiffing of bartenders 


\section{Exhibit 3:}

Descriptive Statistics for Variables in This Study

\begin{tabular}{|c|c|c|c|c|c|}
\hline & $N$ & Minimum & Maximum & Mean & Standard Deviation \\
\hline \multicolumn{6}{|l|}{ Demographics } \\
\hline Age & 824 & 17 & 86 & 43.06 & 16.22 \\
\hline $\operatorname{Sex}(I=$ male, $2=$ female $)$ & 822 & I & 2 & 1.68 & 0.47 \\
\hline School & 827 & I & 7 & 4.69 & 1.34 \\
\hline Income & 818 & I & 9 & 5.30 & 2.42 \\
\hline Race $(\mathrm{I}=$ white, $2=$ black $)$ & 795 & I & 2 & 1.46 & 0.50 \\
\hline \multicolumn{6}{|l|}{$\begin{array}{l}\text { Awareness of tipping norms }(0=\text { not } \\
\text { aware, } I=\text { aware }) \text { for: }\end{array}$} \\
\hline Waiters (any \% norm) & 828 & .00 & 1.00 & .83 & .38 \\
\hline Waiters (I5-20\% norm) & 828 & .00 & 1.00 & .42 & .49 \\
\hline Bartenders & 827 & .00 & 1.00 & .86 & .34 \\
\hline Hair cutters & 825 & .00 & 1.00 & .87 & .34 \\
\hline Parking valets & 819 & .00 & 1.00 & .89 & .31 \\
\hline Pizza delivery drivers & 819 & .00 & 1.00 & .92 & .27 \\
\hline Taxicab drivers & 808 & .00 & 1.00 & .63 & .48 \\
\hline \multicolumn{6}{|l|}{ Restaurant tipping behavior } \\
\hline Tip type $(0=$ flat tip, $\mathrm{I}=$ percentage tip) & 795 & .00 & 1.00 & .73 & .44 \\
\hline Percentage tip & 588 & 8.50 & 22.50 & 16.14 & 3.42 \\
\hline \multicolumn{6}{|l|}{ Frequency of stiffing (not tipping) } \\
\hline Bartenders & 474 & I & 3 & 1.39 & 0.61 \\
\hline Hair cutters & 681 & I & 3 & 1.42 & 0.68 \\
\hline Parking valets & 469 & I & 3 & 1.38 & 0.64 \\
\hline Pizza delivery drivers & 686 & I & 3 & 1.28 & 0.55 \\
\hline Taxicab drivers & 447 & I & 3 & 1.70 & 0.83 \\
\hline
\end{tabular}

\section{Exhibit 4:}

Results of Tests of Norm Awareness as a Mediator of Race Effects on Tipping

\begin{tabular}{lccc}
\hline $\begin{array}{l}\text { Tipping Norms (and Behavior) } \\
\text { When Service Provider Is A: }\end{array}$ & $\begin{array}{c}\text { Coefficient (and Standard Error) of } \\
\text { Race Effects on Norm Awareness }{ }^{\mathrm{a}}\end{array}$ & $\begin{array}{c}\text { Coefficient (and Standard Error) } \\
\text { of Norm Awareness Effects } \\
\text { on Tipping Behavior }^{\mathrm{a}}\end{array}$ & $\begin{array}{c}\text { Sobel } \\
\text { Test }\end{array}$ \\
\hline Waiter (tip type) & $-0.15^{* * *}(.03)$ & $0.62^{* * *}(.04)$ & $-5.96^{* * * *}$ \\
Waiter (percentage tip) & $-0.27^{* * *}(.03)$ & $3.04 * * *(.25)$ & $-6.53^{* * *}$ \\
Bartender (stiff) & $-0.02(.03)$ & $-1.30^{* * *}(.12)$ & 0.96 \\
Hair cutter (stiff) & $-0.09^{* * *}(.03)$ & $-1.20^{* * *}(.08)$ & $3.53^{* * *}$ \\
Parking valet (stiff) & $-0.03(.02)$ & $-1.06 * * *(.11)$ & 1.17 \\
Pizza delivery driver (stiff) & $-0.06^{* *}(.02)$ & $-1.09 * * *(.09)$ & $3.00^{* * *}$ \\
Taxicab driver (stiff) & $-0.03(.04)$ & $-1.22^{* * *}(.07)$ & 0.80 \\
\hline
\end{tabular}

aControlling for respondents' age, sex, education, and income.

$* * p<.01$. **** $<.001$.

(Sobel test $=0.96$, n.s.), parking valets $($ Sobel test $=1.17$, n.s.), or taxicab drivers (Sobel test $=0.80$, n.s.).

The reliable mediation effects observed for some of the race differences in tipping mean that those race differences would be smaller if race differences in norm awareness could be eliminated. Eliminating race differences in tipping norm awareness was not possible in this study, but the effects of those race differences in norm awareness on tipping behavior could be eliminated statistically. A comparison of the effects of race on tipping behavior both before and after statistically controlling for norm awareness is presented in Exhibit 5. These analyses indicate that controlling for awareness of the appropriate tipping norm reduces race differences in restaurant tip type by 43 percent, in restaurant tip percentages by 31 percent, in stiffing of hair cutters by 30 percent, and in stiffing of pizza delivery drivers by 17 percent.

These percentages would be a reasonable estimate of the magnitude of the reduction in race differences in tipping behavior achievable by eliminating race differences in norm awareness, provided norm awareness affects tipping behavior for blacks as much as it does for whites.

Norm awareness as moderator. I investigated that assumption in regression analyses that controlled for respondents' age, sex, education, and income while testing the main and 
Exhibit 5:

Coefficients (and Standard Errors) for Race from Regression Analyses with and without Controls for Awareness of Tipping Norms

\begin{tabular}{|c|c|c|c|}
\hline Dependent Variables & $\begin{array}{l}\text { Models without Norm } \\
\text { Awareness Controls }{ }^{\mathrm{a}}\end{array}$ & $\begin{array}{l}\text { Models with Norm } \\
\text { Awareness Controls }\end{array}$ & $\begin{array}{l}\text { Percentage } \\
\text { Change }\end{array}$ \\
\hline \multicolumn{4}{|l|}{ Restaurant tipping } \\
\hline Tip type & $-0.21^{* * *}(.03)$ & $-0.12 * * *(.03)$ & -43 \\
\hline Percentage tip & $-2.29 * * *(.29)$ & $-1.59 * * *(.26)$ & -31 \\
\hline \multicolumn{4}{|l|}{ Stiffing } \\
\hline Bartenders & $0.28 * * *(.06)$ & $0.23 * * *(.05)$ & -18 \\
\hline Hair cutters & $0.33^{* * * *}(.05)$ & $0.23 * * *(.05)$ & -30 \\
\hline Parking valets & $0.15^{*}(.06)$ & $0.12 *(.06)$ & -20 \\
\hline Pizza delivery drivers & $0.24 * * *(.04)$ & $0.20 * * *(.04)$ & -17 \\
\hline Taxicab drivers & $0.33 * * *(.08)$ & $0.22 * * *(.06)$ & -33 \\
\hline
\end{tabular}

aThese analyses did control for respondents' age, sex, education, and income.

$* p<.05 . * * * p<.001$.

Exhibit 6:

Statistics for the Interaction between Norm Awareness and Race

\begin{tabular}{lccc}
\hline $\begin{array}{l}\text { Dependent Variables } \\
\text { Error }\end{array}$ & Coefficient & $\begin{array}{c}\text { Standard } \\
\text { Error }\end{array}$ \\
\hline $\begin{array}{l}\text { Restaurant Tipping } \\
\quad \text { Tip type }\end{array}$ & 733 & -.13 & .08 \\
$\quad$ Percentage tip & 544 & .44 & .52 \\
Stiffing & & & \\
$\quad$ Bartenders & 438 & .24 & .25 \\
$\quad$ Hair cutters & 625 & .18 & .16 \\
Parking valets & 424 & .34 & .21 \\
Pizza delivery drivers & 628 & .06 & .20 \\
$\quad$ Taxicab drivers & 400 & .26 & .14 \\
\hline
\end{tabular}

These regression analyses controlled for respondents' age, sex, education, and income as well as for the main effects of race and norm awareness.

interaction effects of race and norm awareness. The critical results of these analyses are presented in Exhibit 6, and the interactions are depicted in Exhibits 7 and 8. No interactions were statistically significant, meaning that awareness of tipping norms affects the tipping behavior of blacks the same as it does that of whites. These results are consistent with my 2009 finding that blacks and whites are equally likely to say they tip to follow social norms and lend some support to the validity of those self-reports. They also suggest, together with the mediation analyses reported above, that educating blacks about tipping norms will reduce black-white differences in tipping behavior - by about 30 percent each in the cases of tipping restaurant servers and hair cutters.

\section{Toward an Educational Campaign}

The results of this study indicate that awareness of tipping norms partially mediate but do not moderate race differences in tipping behaviors. These findings support the hypothesis I
Exhibit 7:

Interactions of Norm Awareness with Race as They Affect Restaurant Tipping

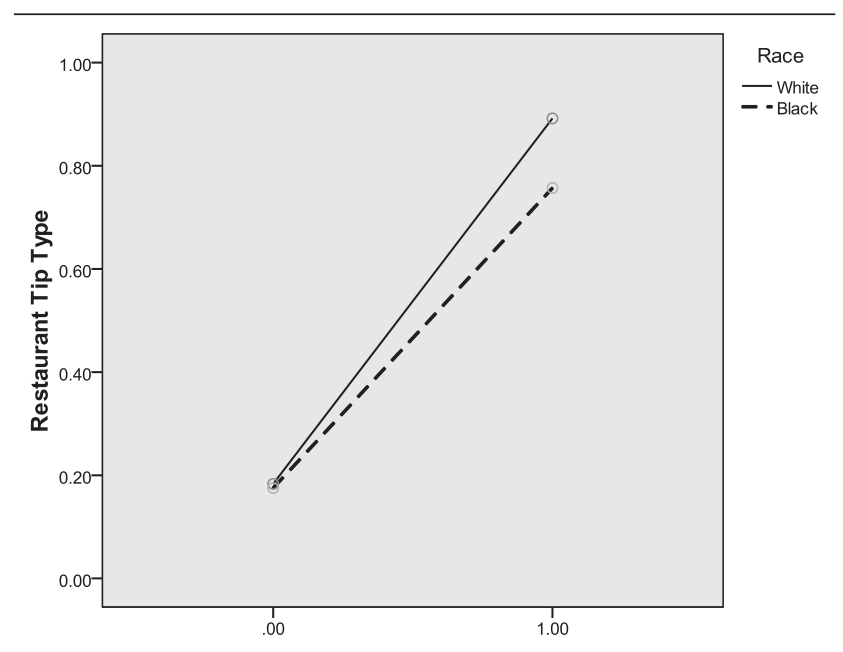

Awareness of Norm to Tip a Percentage of the Bill

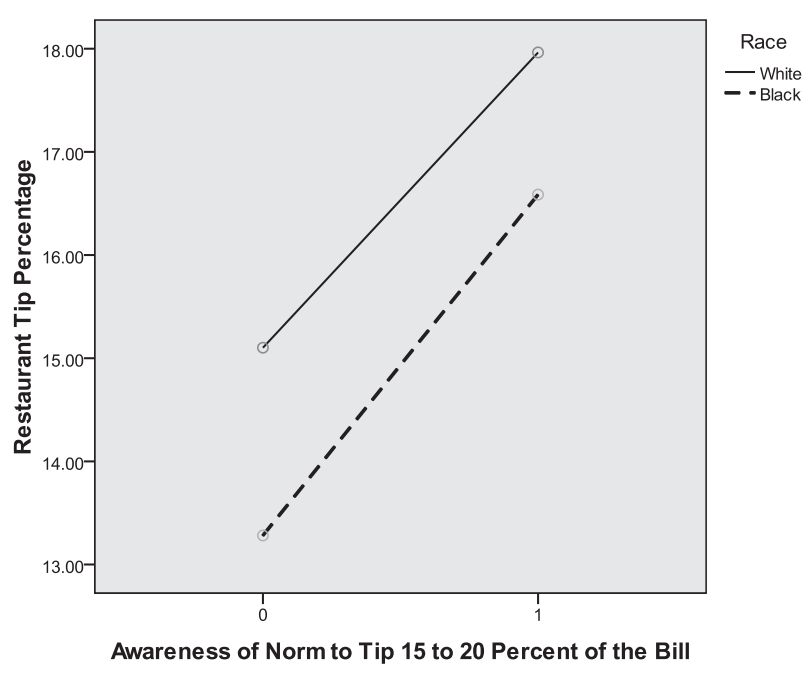




\section{Exhibit 8:}

Interactions of Norm Awareness with Race as They Affect Stiffing of Various Service Providers

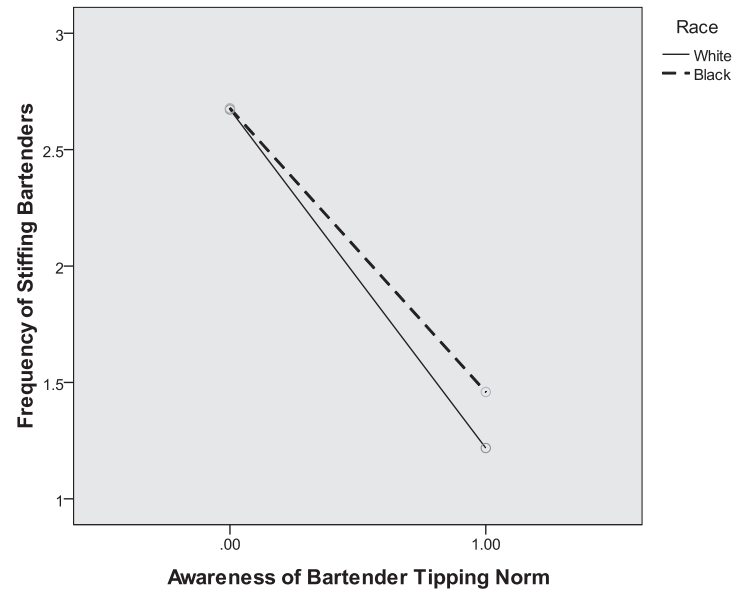

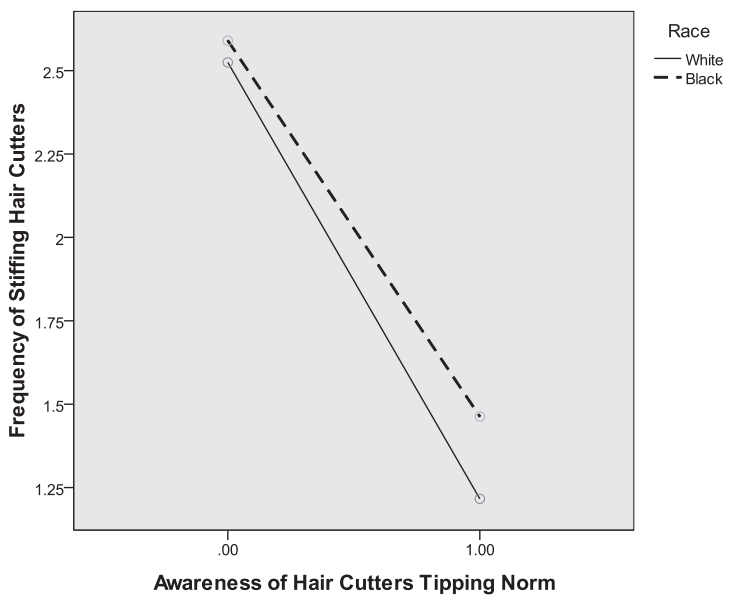

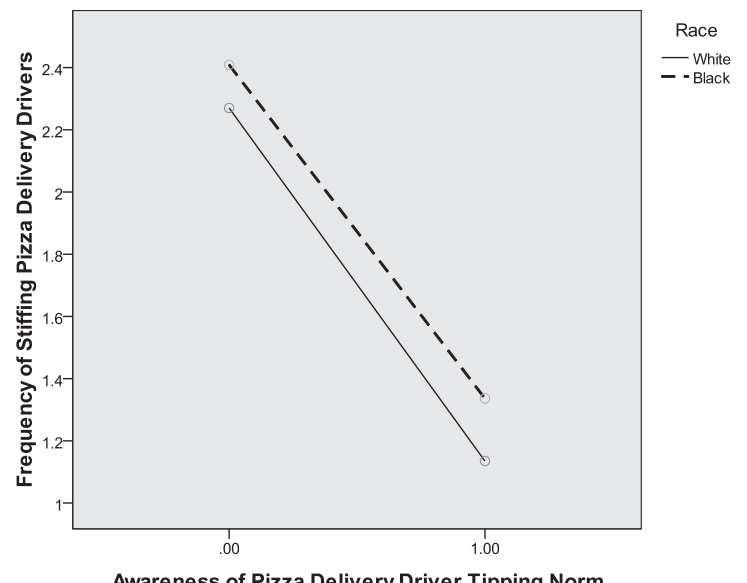

Awareness of Pizza Delivery Driver Tipping Norm
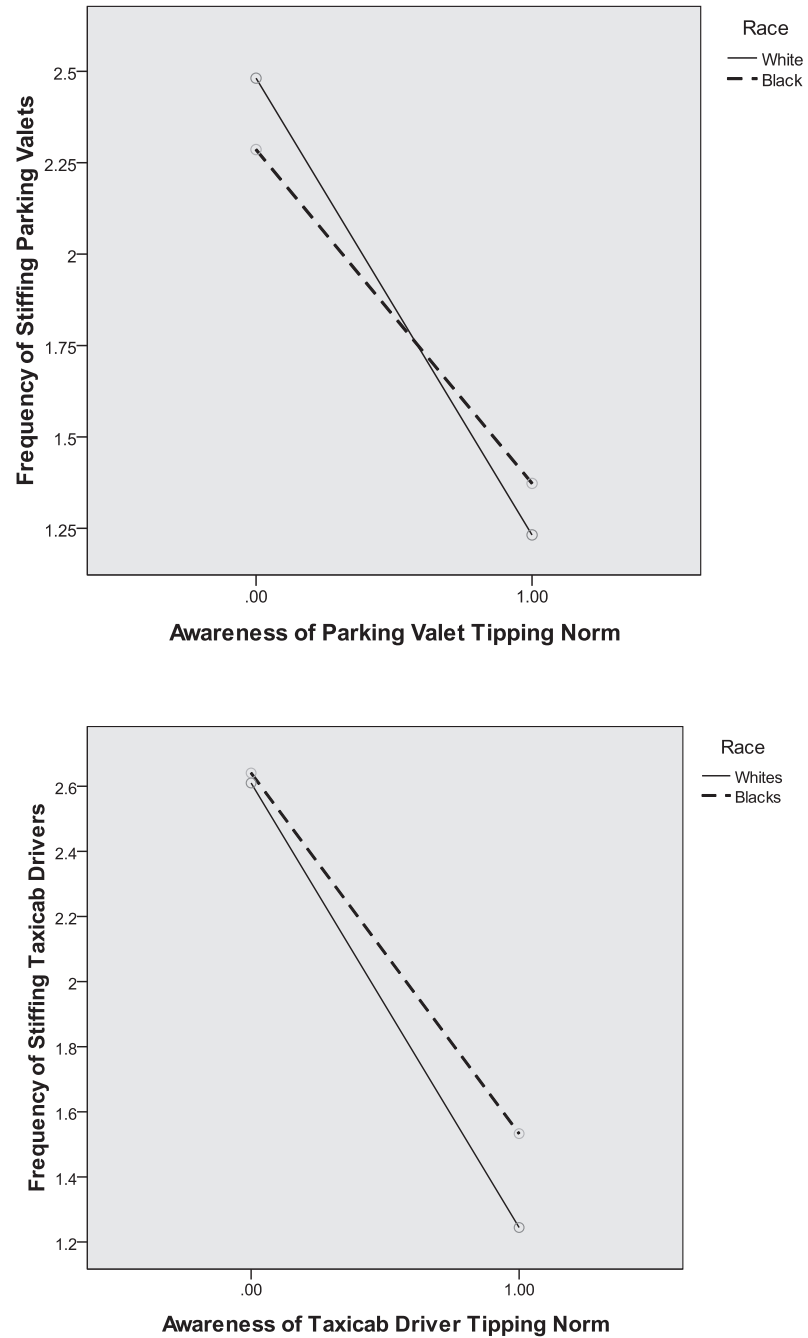
offered in a 2004 study that race differences in tipping are due (at least in part) to race differences in awareness of appropriate tipping norms, as well as my supposition that race differences in tipping can be reduced by educating people about tipping norms. Ideally, large industry organizations, like the National Restaurant Association (NRA) or the Multicultural Foodservice and Hospitality Alliance (MFHA), would solicit funding for and organize a multimedia campaign promoting the 15 to 20 percent restaurant norm. To facilitate people's internalization of the restaurant tipping norm, this campaign should inform people that restaurant servers make less than the minimum wage and depend on tips as the main source of their income. To enhance the social pressure people feel to comply with the restaurant tipping norm, the campaign should also tell people that 15 to 20 percent tips are expected and that most people in this country do tip in that range.

Despite repeated calls for such a campaign (see Amer 2002; Lynn 2004b), the industry seems unwilling or unable to make it happen. Interestingly, the black community itself is beginning to take action. An African American freelance writer, Linda Wallace, has teamed up with several black newspapers to educate blacks about tipping norms, and this award-winning campaign has received support from at least one other black media outlet (Ajanaku 2008; Mays 2008; Wallace 2008). Although the reach of this campaign is limited, I hope it will inspire others to join in and will eventually become more widespread. Perhaps the NRA or MFHA could be persuaded to support this effort.

I also suggest that restaurant managers should educate their own customers about the tipping norm. One tool managers can use to do this is a "Tipping Quiz" that I developed and made available free of charge at the Cornell Center for Hospitality Research's website (http://www.hotelschool .cornell.edu/research/chr/pubs/tools/). This quiz about tipping, which can be printed on table tents or on menu inserts, allows people to score their own knowledge about tipping. Customers taking the quiz and looking at the answers will learn about all the issues described above that should be addressed in an educational campaign. Since this quiz does not mention race differences in tipping and is likely to be viewed as interesting and fun by consumers, putting it on table tents or menu inserts should be a low-risk way to increase awareness of the restaurant tipping norm and reduce race differences in tipping.

Although norm awareness does mediate race differences in tipping, that mediation is only partial. The data from this study suggest that completely eliminating race differences in awareness of the 15 to 20 percent restaurant tipping norm will reduce race differences in restaurant tip percentages by only about 30 percent. In other words, these data suggest that a substantial race difference in tipping will still exist even if blacks' awareness of the tipping norm is brought up to that of whites. Thus, an educational campaign promoting tipping norms is only a partial solution to the industry problems stemming from race differences in tipping. Furthermore, educational campaigns will have no effect in service settings like bartending, car parking, and taxicab driving where there are no race differences in awareness of tipping norms to explain the race differences in tipping.

To fully address the issue of race differences in tipping, we need to better understand and address all the causes of those differences. Unfortunately, it is not clear what is causing those race difference in tipping that persist after controlling for norm awareness. It is not differences in income, education, or service quality, because the effects of those factors were also controlled for in this study. Thus, identifying and testing other potential explanations for race differences in tipping is an important task left for future researchers.

\section{Declaration of Conflicting Interests}

The author(s) declared no conflicts of interest with respect to the authorship and/or publication of this article.

\section{Funding}

The author(s) received no financial support for the research and/or authorship of this article.

\section{References}

Ajanaku, Karanja A. 2008. Tri-state defender nets award in national competition. http://tri-statedefenderonline.com/articlelive/ articles/2676/1/Tri-State-Defender-nets-award-in-nationalcompetition/Page1.html (accessed September 30, 2009).

Amer, Suzie. 2002. Minority report. Restaurant Business, November 15, pp. 27-38.

Baron, Rueben, and David Kenny. 1986. The moderator-mediator variable distinction in social psychological research: Conceptual, strategic and statistical considerations. Journal of Personality and Social Psychology 51:1173-82.

Lynn, Michael. 2004a. Black-white differences in tipping of various service providers. Journal of Applied Social Psychology 34:2261-71.

Lynn, Michael. 2004b. Ethnic differences in tipping: A matter of familiarity with tipping norms. Cornell Hotel and Restaurant Administration Quarterly 45:12-22.

Lynn, Michael. 2006. Geodemographic differences in knowledge about the restaurant tipping norm. Journal of Applied Social Psychology 36:740-50.

Lynn, Michael. 2009. Individual differences in self-attributed motives for tipping: Antecedents, consequences, and implications. International Journal of Hospitality Management 28:432-38.

Lynn, Michael, Michael Sturman, Christie Ganley, Elizabeth Adams, Mathew Douglas, and Jessica McNeil. 2008. Consumer racial discrimination in tipping: A replication and extension. Journal of Applied Social Psychology 38:1045-60. 
Lynn, Michael, and Clorice Thomas-Haysbert. 2003. Ethnic differences in tipping: Evidence, explanations and implications. Journal of Applied Social Psychology 33:1747-72.

Mays, Myron. 2008. The big question: Do you tip when you dine out? If not, why not? http://tri-statedefenderonline.com/articlelive/ articles/2685/1/The-Big-Question--Do-you-tip-when-you-dineout-If-not-why-not/Page1.html (accessed September 30, 2009).

McCall, Michael, and Ann Lynn. 2009. Restaurant servers' perceptions of customer tipping intentions. International Journal of Hospitality Management 28:594-96.

Rusche, Sarah, and Zachary Brewster. 2008. "Because they tip for shit": The social psychology of everyday racism in restaurants. Sociology Compass, February 6, pp. 2008-29.
Wallace, Linda. 2001. The restaurant wars: Dare to go where no broker has gone before. DiversityInc.com (accessed August 9, 2001).

Wallace, Linda. 2008. The tipping gamble: Good service today, insults tomorrow. http://tri-statedefenderonline.com/articlelive/ articles/2728/1/The-Tipping-Gamble-Good-service-todayinsults-tommorrow/Page1.html (accessed September 30, 2009).

\section{Bio}

Michael Lynn, Ph.D., is the Burton M. Sack '61 Professor in Food and Beverage Management at the School of Hotel Administration, Cornell University (WML3@cornell.edu). Review and acceptance of this manuscript was managed by former editor Linda Canina. 